\title{
Effect of Various Bedding Conditions on Structural Integrity of Prestressed Concrete Cylinder Pipe
}

\author{
Shaoqing $\mathrm{Ge}^{1} \&$ Sunil Sinha ${ }^{1}$ \\ ${ }^{1}$ Department of Civil and Environmental Engineering, Virginia Tech, USA \\ Correspondence: Shaoqing Ge, Department of Civil and Environmental Engineering, Virginia Tech, USA. E-mail: \\ geshao@vt.edu
}

Received: December 31, 2014 Accepted: January 9, 2015 Online Published: March 2, 2015

doi:10.5539/jmsr.v4n2p34 URL: http://dx.doi.org/10.5539/jmsr.v4n2p34

\begin{abstract}
Prestressed Concrete Cylinder Pipe (PCCP) is one pipe material mainly used in large-diameter and high-pressure transmission main or force main. PCCP was widely used in large utilities because of its low cost and relatively good performance in its early stage of life. However, as PCCP approaches to the end of life, more failures occur. PCCP failures usually occur suddenly without any warning and cause catastrophic consequences, including great economic, societal, and environmental losses. Many factors can cause PCCP failures including design and manufacture, construction and operation, and environmental factors. Among these factors, bedding condition has been identified in forensic studies as a critical factor, especially in mountain areas with rock bedding. However, PCCPs are generally assumed to be rigid pipe and they are placed in poor bedding in some constructions, thus causing pipe failures. In current numerical models used to evaluate structural condition of PCCP, one of the major limitations is inadequate consideration of bedding conditions.

This paper analyzes the effect of various bedding conditions on structural integrity of PCCP. A numerical model is developed and the properties of different bedding materials are considered. The pipe components such as coating, prestressing wires, concrete core, and steel cylinder are taken into account. The results of the analysis are summarized and compared. The research presented in this paper provides a better understanding of the importance of good bedding for PCCP. The findings of this research can help utilities better management their PCCP pipelines in various bedding conditions.
\end{abstract}

Keywords: prestressed concrete cylinder pipe, pccp failure, condition evaluation, numerical model

\section{Introduction}

Prestressed Concrete Cylinder Pipe (PCCP), unlike other pipes made of single material, is composed of several materials including concrete, steel cylinder, mortar coating and prestressing wires. Among these materials, high-strength prestressing wire is the primary component which is wrapped to a certain prestress to keep concrete core in compression. Compressed concrete core can then withstand high internal pressure and external earth load. The mortar coating serves to protect the wire against corrosion by providing alkaline environment (Price et al., 1998; Wardany, 2008). The steel cylinder serves as water barrier to seal water from leaking (AWWA C301-07, 2007; ANSI/AWWA C304-07, 2007).

In general, PCCP has lower break rate compared with other pipe materials. PCCPs manufactured in 1970s have more failures because of the adoption of class IV prestressing wire which is more sensitive to hydrogen embrittlement during corrosion. PCCP failures can be catastrophic due to its high pressure and large diameter. The water released at failures can destroy neighboring structures, wash away highways, and flush home, etc. with consequence of over millions of dollars. In addition, significant financial investment is required for pipeline inspection and repairs (Bell, 2001; Essamin et al., 2005; Galleher \& Stift, 1998). In 2010, a 72-inch PCCP sewer force main failed in Florida and over 15 million gallons of untreated wastewater went into Biscayne Canal. The utility owing this pipeline had to spend over 1 million dollars to fix the pipe, and received a civil penalty of approximately 1 million dollars (UIM, 2011; USEPA, 2013).

PCCP failures are caused by many factors which can be grouped into three categories: manufacture and design (poor bond, low prestress, poor material, etc.), construction and operation (poor bedding, construction damage, etc.), and environmental (corrosive soil, chloride, etc.) (Lewis, 2002). PCCP failure is a complex process which in 
general is initiated with "birth defects" such as cracks in coating due to damage during manufacture and construction, or operational damage due to overloading. Then chemicals in soil reach the prestressing wires and steel cylinder via cracks, and corrosion starts. Prestressing wires suffer hydrogen embrittlement because of the hydrogen produced in corrosion process and then break. A certain number of broken wires weaken the pipe structure and then concrete core collapses and cylinder bursts (Price et al., 1998; Woodcock, 2008a; Romer et al., 2008; Kola, 2010; Ge \& Sinha, 2014).

Among those failure factors, bedding condition is very important because poor bedding could cause high stress and generate cracks in the coating, thus leading to corrosion in the prestressing wires and cylinder (Woodcock, 2008b). There have been several cases in which rocks in bedding caused severe PCCP failure. One 66-inch PCCP failed on December 23, 2008, on River Road, Maryland. Large volume of water released out and created a flowing river, stranding people in cars and helicopters were sent out rescue them (see Figure 1). The repair of this pipeline cost approximately $\$ 1.7$ million and millions of gallons water was lost (WSSC, 2012). In the following forensic study, it was found that the damage to the coating caused the pipe failure which was due to the pipe being supported directly by rock.

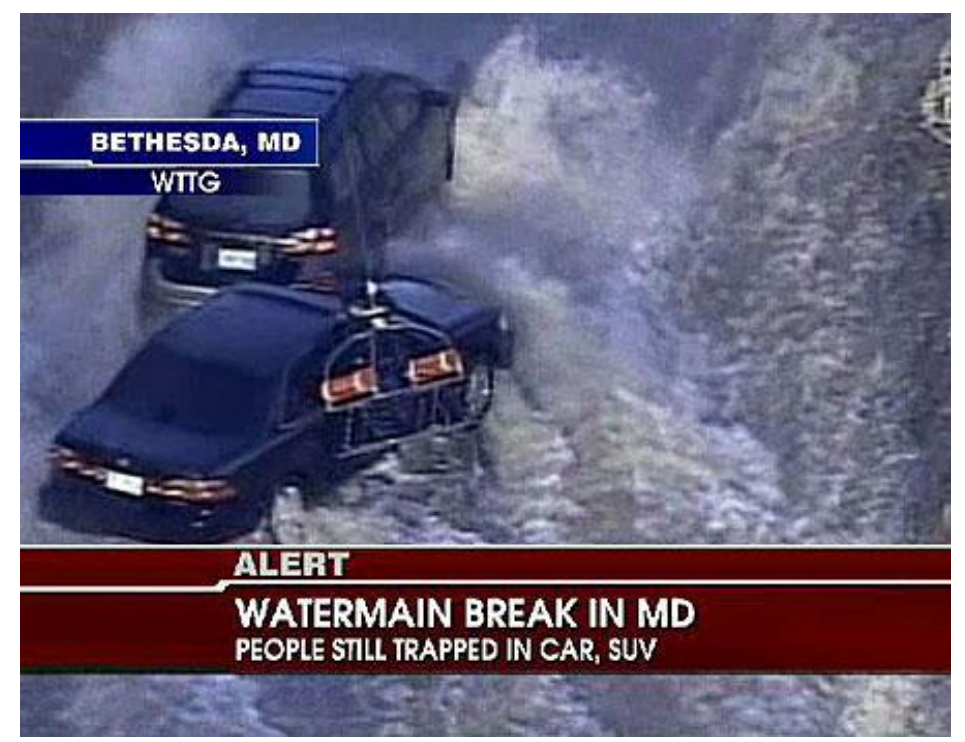

Figure 1. People rescued by helicopter in 66-inch PCCP main break (FoxNews, 2014)

To avoid catastrophic failures of PCCP, considerable research has been conducted to develop various models and to evaluate the condition of the pipe so that proactive measures can be taken before the pipe fails. This includes models based on probabilistic/statistical, or advanced mathematical models (Bradish et al., 1995; Kleiner et al., 2004; Marshall et al., 2005; Nelson, 2005; Rajani et al., 2006; Amaitic and Amaitic, 2008; AwwaRF, 2008), and numerical models (Zarghamee et al., 1993, 2001, 2002, 2003, 2006; Diab \& Bonierbale, 2001; Gomez et al., 2004; Erbay et al., 2007; Weare, 2007; Alavinasab et al., 2010; Xiong et al., 2010; Lee, 2011; Rauniyar, 2013). The merits and limitations of these models were systematically summarized in previous literature (Ge \& Sinha, 2014).

Among these models, numerical models have advantage over other models because factors that directly affect the condition of the pipe such as loading, pipe dimensions, and material properties are considered. However, current numerical models have limitations due to inadequate consideration of bedding conditions of the pipe (Ge \& Sinha, 2014).

In this paper, a numerical model considering various bedding conditions is developed. The effect of bedding condition on structural integrity is evaluated by considering the properties of different bedding materials. This research will help engineers in better management of their PCCP pipelines and provide guidance in developing numerical models for PCCP as well.

\section{Numerical Model for PCCP Considering Various Bedding Conditions}

In this research, a numerical model is developed using finite element method (FEM) to evaluate the effect of several typical bedding conditions found in practice. The pipe components such as mortar coating, concrete core, 
prestressing wires, and steel cylinder are considered. The concrete core, coating, steel cylinder, soil, rock, and sand are simulated using 3-dimentional 8-node brick elements (C3D8R), the prestressing wires are simulated using 3-dimensional truss element (T3D2). The prestress in the prestressing wire is applied by temperature-drop method. The thermal stress in the wire is generated due to temperature drop. The interaction between cylinder and concrete cores are simulated using general contact, while the interaction between the mortar coating and concrete core is simulated using surface-based cohesive behavior. It is assumed that there is not delamination between the soil and the pipe.

Loadings such as weight of soil, pipe, water inside the pipe, and internal/surge pressure are considered in the model. The FE model (with rock bedding) is shown in Figure 2. For boundary conditions, the nodes on the bottom surface of the model are fully fixed; the nodes on top surface of the model are free; the nodes on the surfaces of other four sides of the model are fixed in the normal direction of each surface.

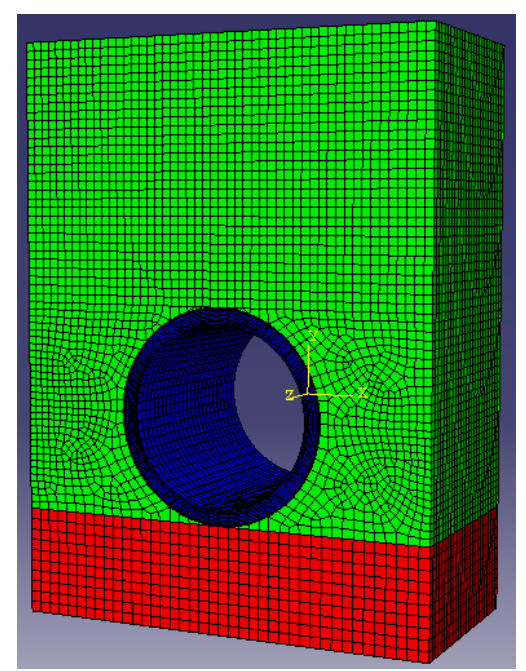

Figure 2. FE model of PCCP with rock bedding (The red part is rock bedding)

The most common bedding problem is rigid bedding in mountain areas where the pipe is placed directly either fully or partially on rock. In this research, four different bedding conditions are analyzed and the results are summarized:

1) Case 1: Pipe sits directly on rock (see Figure 3), with rock bedding depth of $1 \mathrm{~m}$ (39.37 inch).

2) Case 2: Pipe sits on half rock and half sand (see Figure 4), with the sand depth of $0.20 \mathrm{~m}(8$ inch) and width of $2 \mathrm{~m}(78.64$ inch)

3) Case 3: Pipe sits on sand bedding with rock base (see Figure 5), the bedding layer is $0.20 \mathrm{~m}(8 \mathrm{inch})$

4) Case 4: Pipe sits on soil bedding with soil base (see Figure 6)

In these four cases, the pipe is subject to the same loading for comparison purposes: soil and pipe weight, internal pressure 1.38e6 $\mathrm{Pa}(200 \mathrm{psi})$, and surge pressure 5.52e $5 \mathrm{~Pa}$ (80 psi). The pipe dimensions are listed below:

- $\quad$ Pipe diameter: $1.68 \mathrm{~m}$ (66 inch)

- Cylinder thickness: $1.40 \mathrm{~mm}$ (0.05 inch)

- Concrete core thickness: $0.13 \mathrm{~m}$ (5.00 inch)

- Coating thickness: $0.02 \mathrm{~m}$ (0.81 inch)

- Wire spacing: $0.01 \mathrm{~m}(0.43 \mathrm{inch})$

- $\quad$ Buried depth: $2.44 \mathrm{~m}(8 \mathrm{ft})$ 


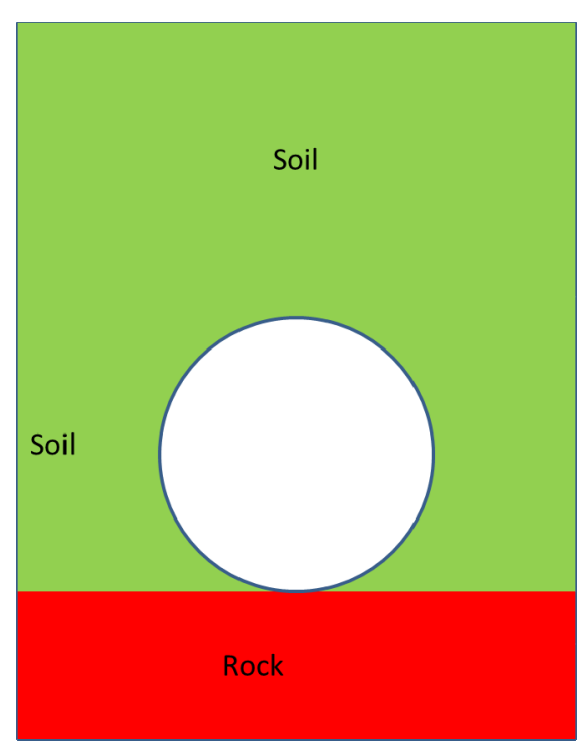

Figure 3. Case 1: Pipe sits directly on rock

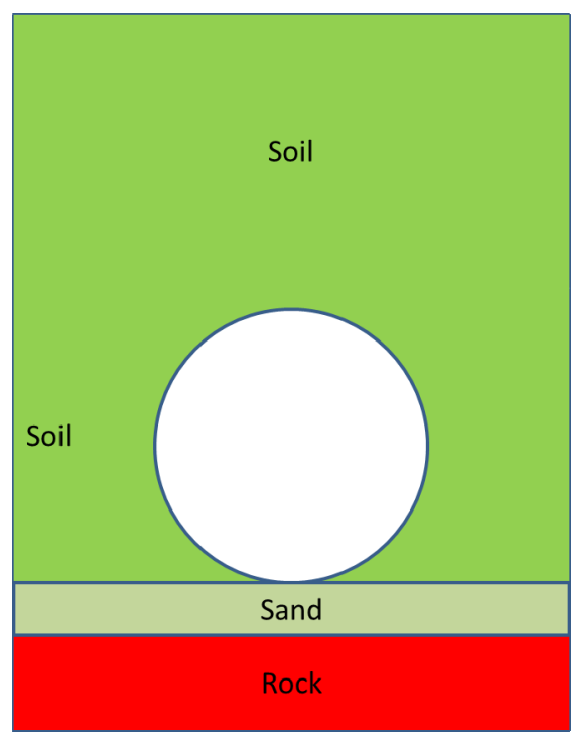

Figure 5. Case 3: Pipe sits on sand bedding with rock base

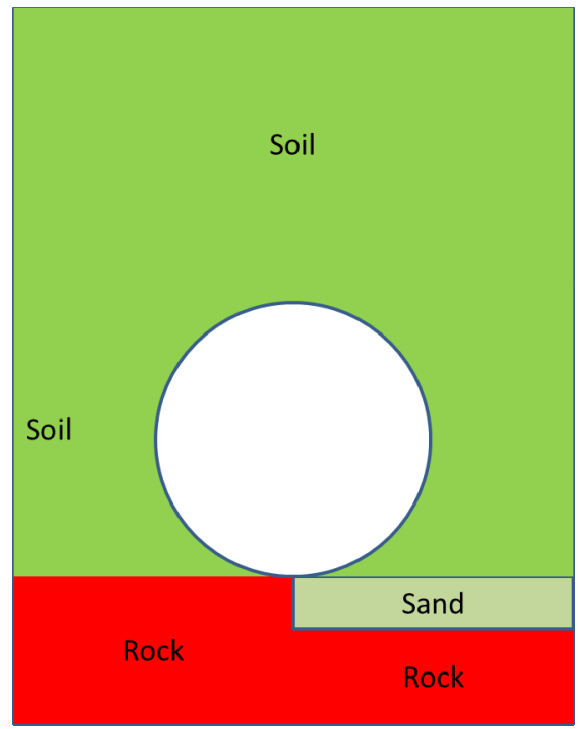

Figure 4. Case 2: Pipe sits on half rock and half sand

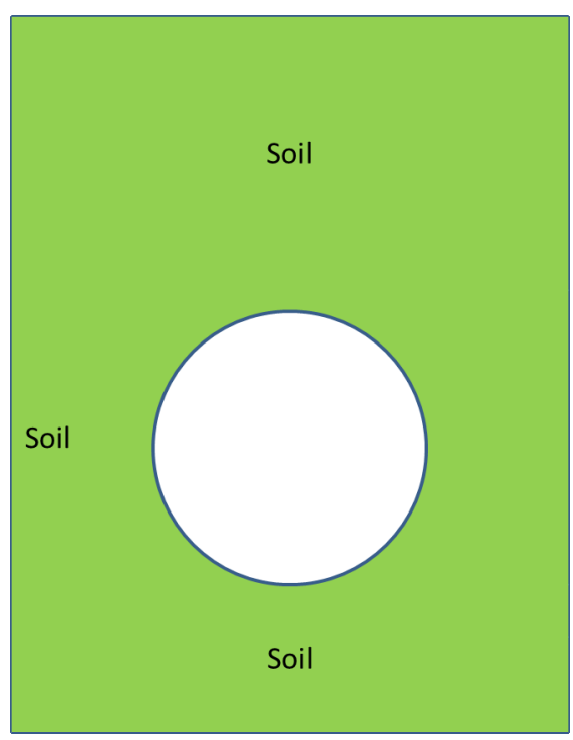

Figure 6. Case 4: Pipe sits on soil bedding with soil base

The material properties used are listed in Table 1 below:

Table 1. Mechanical property of materials

\begin{tabular}{cccc}
\hline Material & Young's Modulus (Pa) & Poisson's Ratio & Density $\left(\mathrm{kg} / \mathrm{m}^{3}\right)$ \\
\hline Concrete & $2.45 \mathrm{e}+10$ & 0.17 & 2322.61 \\
Soil & $6.90 \mathrm{e}+06$ & 0.25 & 1840.00 \\
Prestressing wire & $1.93 \mathrm{e}+11$ & 0.30 & 7832.80 \\
Sand & $3.50 \mathrm{e}+7$ & 0.30 & 1800.00 \\
Rock & $5.58 \mathrm{e}+10$ & 0.18 & 2650.00 \\
Cylinder & $2.07 \mathrm{e}+11$ & 0.30 & 7832.80 \\
\hline
\end{tabular}

Other properties of the materials are listed below: Yield strength of the cylinder is $2.28 \mathrm{e}+8 \mathrm{~Pa}(33,000 \mathrm{psi})$; its ultimate strength is $3.87 \mathrm{e}+8 \mathrm{~Pa}(56,100 \mathrm{psi})$. The wire ultimate strength is $1.45 \mathrm{e}+9 \mathrm{~Pa}(211,000 \mathrm{psi})$; the wrapping 
stress of the wire is $1.09 \mathrm{e}+9 \mathrm{~Pa}(158,250 \mathrm{psi})$. Compressive strength of concrete is $48 \mathrm{MPa}(6,962 \mathrm{psi})$. The tensile strength of concrete is $4.02 \mathrm{MPa}$ (583 psi). The compressive strength of mortar coating is $37.90 \mathrm{MPa}(5,500 \mathrm{psi})$, and tensile strength is $3.57 \mathrm{MPa}(518 \mathrm{psi})$. Only elastic analysis is conducted due to unavailability of plastic properties of coating and concrete core. Coating and concrete follows Rankine Theory of Maximum Stress Theory, while prestressing wire and steel cylinder follow von Mises criteria.

In the analysis of the four cases, the maximum/minimum principal stress in representative points are compared (see Figure 7). The Maximum principal stress at Point 2, 3, and 6 are analyzed; the Minimum principal stress at Point 1, 4, and 5 are analyzed. The relative deformations in horizontal and vertical direction are analyzed as well (see Figure 8).

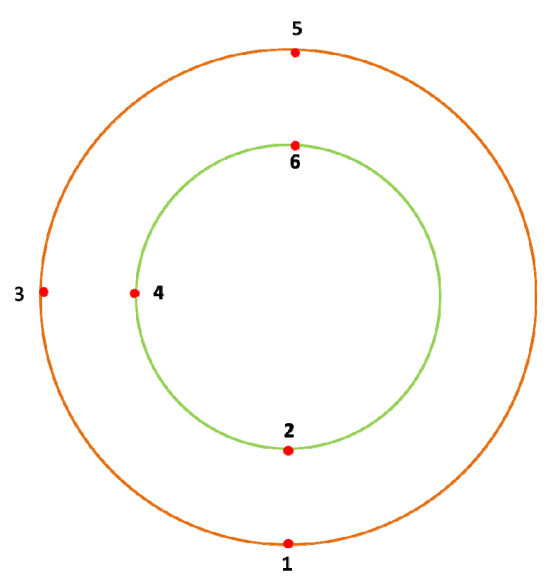

Figure 7. Locations of pipe for stress evaluation

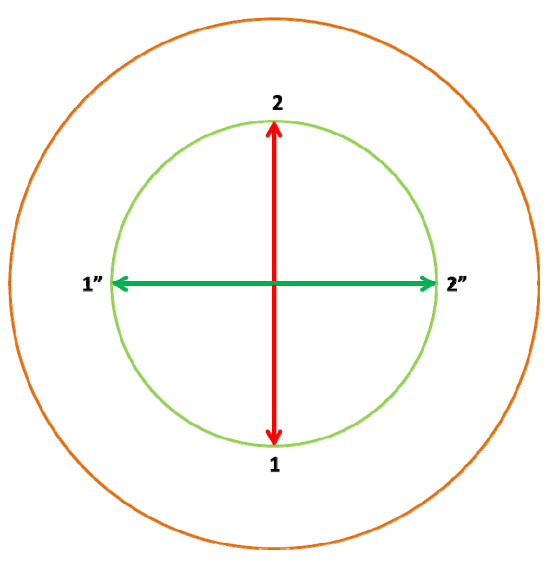

Figure 8. Relative deformations

\section{Case 1: Pipe Sits Directly on Rock}

In this case, the pipe is placed directly on rock. The bottom of the pipe has hard contact with rock. The distribution of maximum and minimum principal stress in PCCP is shown in Figure 9 and Figure 10, respectively. According to Figure 9 and Figure 10, the maximum principal stress at Point 2, 3, and 6 is $6.54 \mathrm{MPa}, 2.00 \mathrm{MPa}$, and $2.23 \mathrm{MPa}$, respectively. The maximum principal stress at Point 2 exceeds the tensile strength of concrete (4.02 MPa), thus cracks occur in this location. Point 3 is at external springline and the $2.00 \mathrm{MPa}$ tensile stress is below the tensile strength of mortar coating (3.57 MPa), hence no cracks would occur at this point. Point 6 is at inner crown and the 2.23 MPa tensile stress is below the concrete tensile strength, and no cracks would occur at this location. The minimum principal stress at Point 1,4 , and 5 is $-9.66 \mathrm{MPa},-6.89 \mathrm{MPa}$, and $-5.00 \mathrm{MPa}$, respectively. Since the compressive strength of concrete and coating is $49.00 \mathrm{MPa}$ and $37.90 \mathrm{MPa}$, respectively, there will be no cracks due to compression in these locations. The vertical and horizontal displacements are $1.73 \mathrm{~mm}$ and $1.39 \mathrm{~mm}$, respectively.

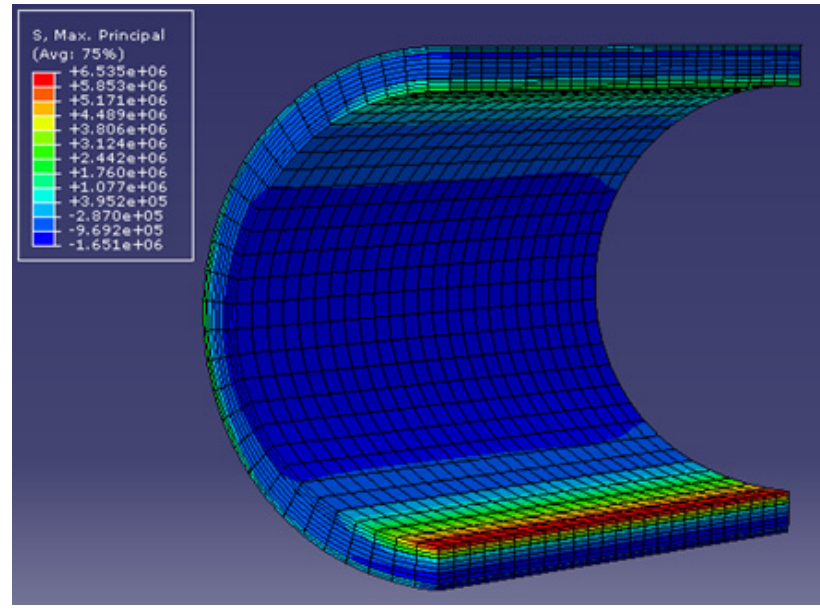

Figure 9. Maximum principal stress in PCCP (Case 1)

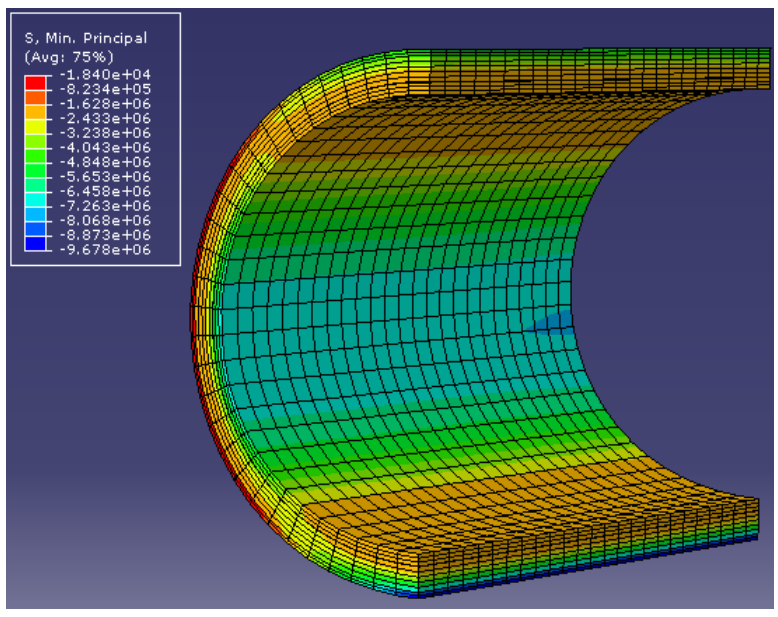

Figure 10. Minimum principal stress in PCCP (Case 1) 


\section{Case 2: Pipe Sits on Half Rock and Half Sand Bedding}

In this case, half of the pipe is placed on rock and the other half is placed on sand. The distribution of maximum and minimum principal stress in PCCP is shown in Figure 11 and Figure 12, respectively. According to Figure 11 and Figure 12, the maximum principal stress at Point 2, 3, and 6 is $6.69 \mathrm{MPa}, 2.05 \mathrm{MPa}$, and 2.26 MPa, respectively. The maximum principal stress at Point 2 exceeds the tensile strength of concrete, hence, cracks occur in this location. The tensile stress at Point 3 is below the tensile strength of mortar coating, so there are no cracks at this point. The tensile stress at Point 6 is below the tensile strength of concrete, so there are no cracks at this location. The minimum principal stress at Point 1,4 , and 5 is $-9.85 \mathrm{MPa},-6.97 \mathrm{MPa}$, and $-5.03 \mathrm{MPa}$, respectively. There will be no cracks due to over compression in these locations. The vertical and horizontal displacements are $1.75 \mathrm{~mm}$ and $1.40 \mathrm{~mm}$, respectively.

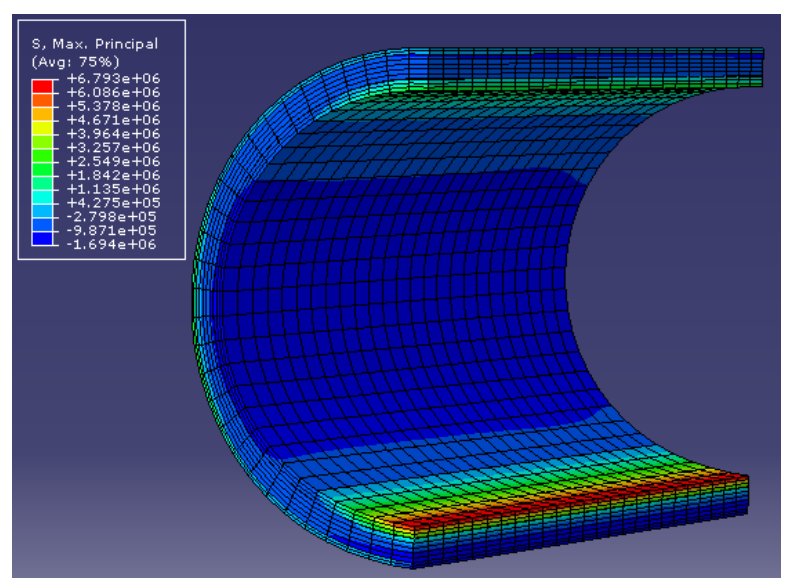

Figure 11. Maximum principal stress in PCCP (Case 2)

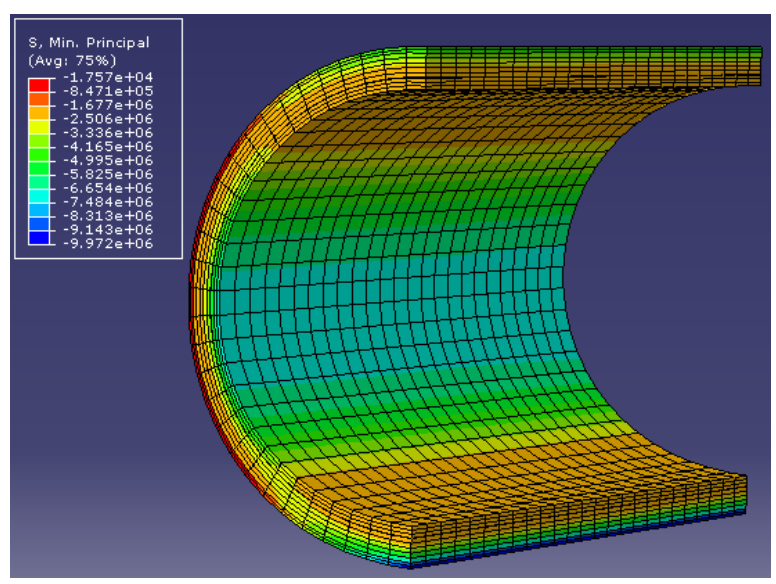

Figure 12. Minimum principal stress in PCCP (Case 2)

\section{Case 3: Pipe Sits on Sand Bedding with Rock Base}

In this case, the pipe is placed on a layer of sand $(0.20 \mathrm{~m}$ thick, around 8 inch), and there is rock beneath the sand. The distribution of maximum and minimum principal stress in PCCP is shown in Figure 13 and Figure 14, respectively. According to Figure 13 and Figure 14, the maximum principal stress at Point 2, 3, and 6 is $3.62 \mathrm{MPa}$, $1.56 \mathrm{MPa}$, and $1.76 \mathrm{MPa}$, respectively. The maximum principal stress at point 2 and 6 is below the tensile strength of concrete (4.02 MPa), so no cracks occur in this location. The tensile stress at point 3 is also below the tensile strength of mortar coating, so no cracks occur at this location either. The minimum principal stress at Point 1,4 , and 5 is $-6.54 \mathrm{MPa},-6.37 \mathrm{MPa}$, and $-4.65 \mathrm{MPa}$, respectively. There will be no cracks due to compression in these locations. The vertical and horizontal displacements are $1.46 \mathrm{~mm}$ and $1.17 \mathrm{~mm}$, respectively.

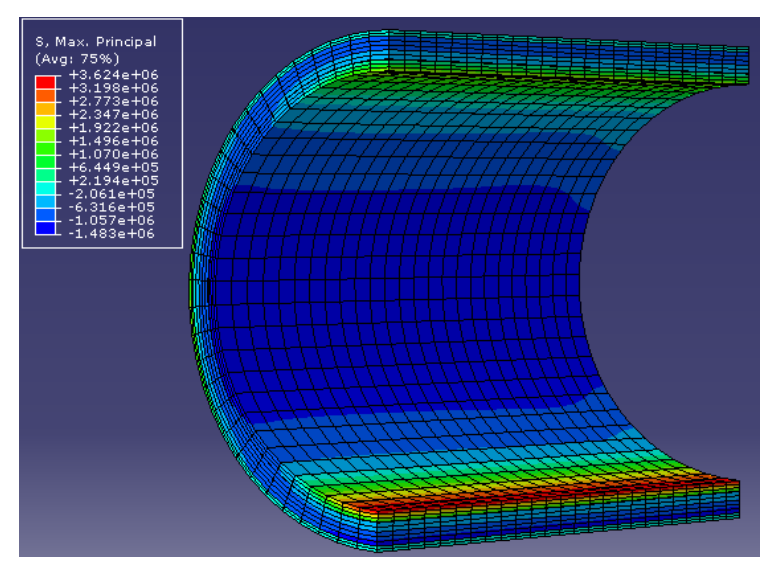

Figure 13. Maximum principal stress in PCCP (Case 3)

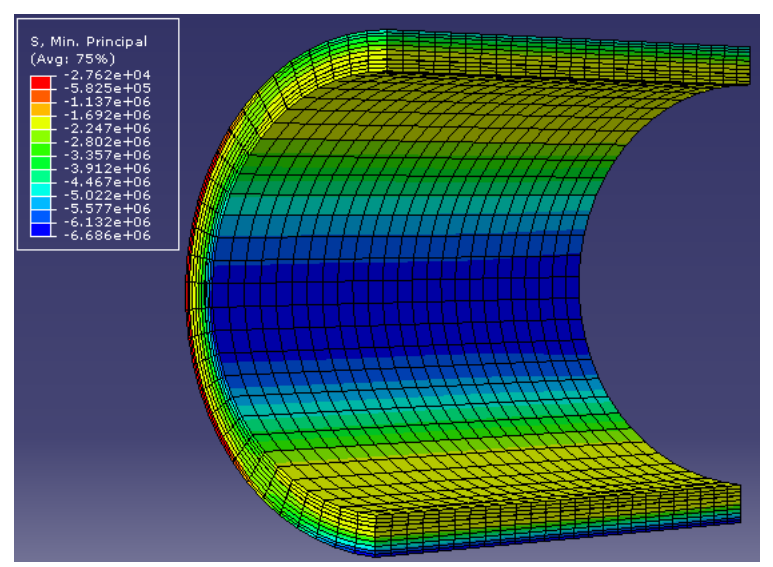

Figure 14. Minimum principal stress in PCCP (Case 3) 


\section{Case 4: Pipe Sits on Soil Bedding with Soil Base}

In this case, the pipe is surrounded by soil and there is no rock in the system. The distribution of maximum and minimum principal stress in PCCP is shown in Figure 15 and Figure 16, respectively. According to Figure 15 and Figure 16, the maximum principal stress at Point 2, 3, and 6 is $1.02 \mathrm{MPa}, 0.61 \mathrm{MPa}$, and $0.79 \mathrm{MPa}$, respectively. The maximum principal stress at all points is below the tensile strength of concrete $(4.02 \mathrm{MPa})$ and mortar coating (3.57 MPa), so no cracks occur in these locations. The minimum principal stress at Point 1, 4, and 5 is $-4.21 \mathrm{MPa}$, $-5.18 \mathrm{MPa}$, and -3.91 MPa, respectively. Since the compressive strength of concrete and mortar coating is 49.00 $\mathrm{MPa}$ and $37.90 \mathrm{MPa}$, respectively, there will be no cracks due to compression in these locations. The vertical and horizontal displacements are $1.01 \mathrm{~mm}$ and $0.77 \mathrm{~mm}$, respectively.

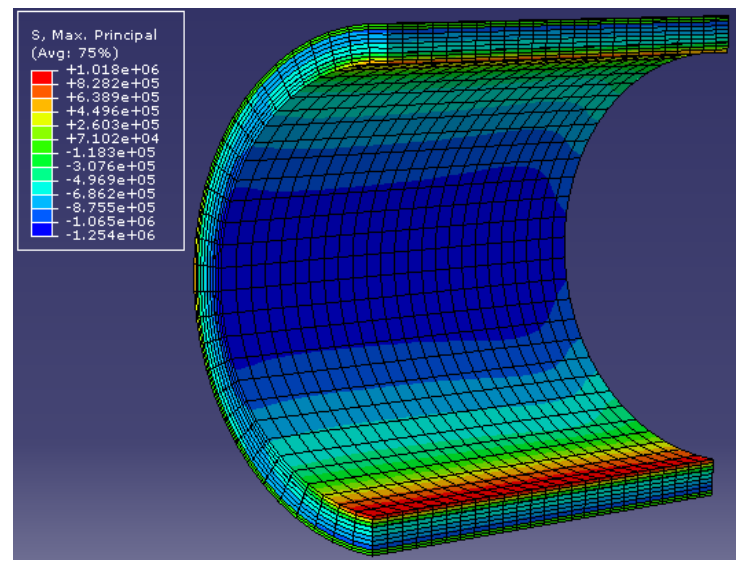

Figure 15. Maximum principal stress in PCCP (Case 4)

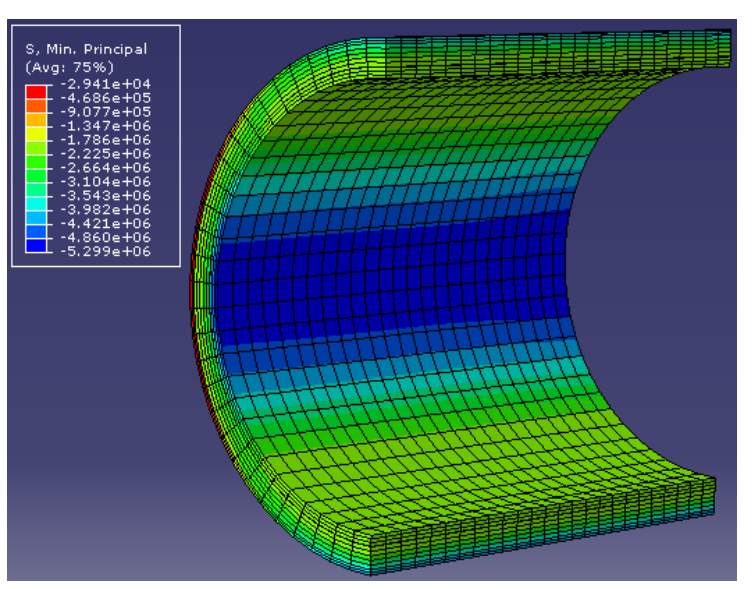

Figure 16. Minimum principal stress in PCCP (Case 4)

\section{Summary of PCCPs WITH VARIOUS BEDDING CONDITIOns}

The maximum and minimum principal stress at representative points is summarized in Table 2 and Figure 17. It can be seen that when the pipe is placed on half rock and half sand bedding (Case 2), point 2 has the highest tensile stress exceeding the tensile strength of concrete, and point 1 has the highest compressive stress, but below the compressive strength of concrete. Case 2 has highest principal stress due to the stress concentration of the pipe at the edge of the rock. This is even worse than Case 1 in which the pipe is placed directly on rock. In case 3 , with a $0.20 \mathrm{~m}$ layers of sand, the highest tensile stress in the pipe is reduced to $3.62 \mathrm{MPa}$, which is lower than the tensile strength of concrete, and there would be no cracks in concrete at point 2 . If the pipe is placed in an all-soil bedding (no rock base), the pipe has lowest tensile stress (1.02 MPa).

The relative deformations of the pipe in horizontal and vertical direction follow the same pattern (see Table 3 and Figure 18). With half pipe placed on rock and the other half place on sand, the pipe has highest horizontal (1.40 $\mathrm{mm})$ and vertical deformation $(1.75 \mathrm{~mm})$. With all soil bedding, the relative deformation of the pipe in horizontal $(0.77 \mathrm{~mm})$ and vertical $(1.00 \mathrm{~mm})$ deformation is the smallest.

In comparison, when the pipe is placed as it does in Case 2 and Case 1, the concrete has very high tensile stress in excess of concrete's tensile strength at inner invert. Compared with Case 1, Case 2 has much higher maximum principal tensile stress because of the half-rock bedding creates stress concentration to the pipe. However, with a layer of sand in Case 3, the highest tensile stress is significantly reduced to $3.62 \mathrm{MPa}$, below the tensile strength of concrete. This indicates the importance of bedding treatment for PCCP, especially in mountain areas. In case 4, the pipe has lowest tensile strength and smallest deformation. In sum, PCCP placed directly on rock or partially directly placed on rock has very bad effect on the pipe's structural integrity. To improve the condition of PCCP, it is important to treat the bedding and place a layer of soft material such as sand to avoid high tensile stress in the pipe and provides more even distribution of stress in the pipe. 
Table 2. Maximum/minimum principal stress at representative points

\begin{tabular}{lcc}
\hline Case No. & Maximum Principal Stress (MPa) at point 2 & Minimum Principal Stress (MPa) at point 1 \\
\hline CASE 1 & 6.54 & -9.66 \\
CASE 2 & 6.69 & -9.85 \\
CASE 3 & 3.62 & -6.54 \\
CASE 4 & 1.02 & -4.21 \\
\hline
\end{tabular}

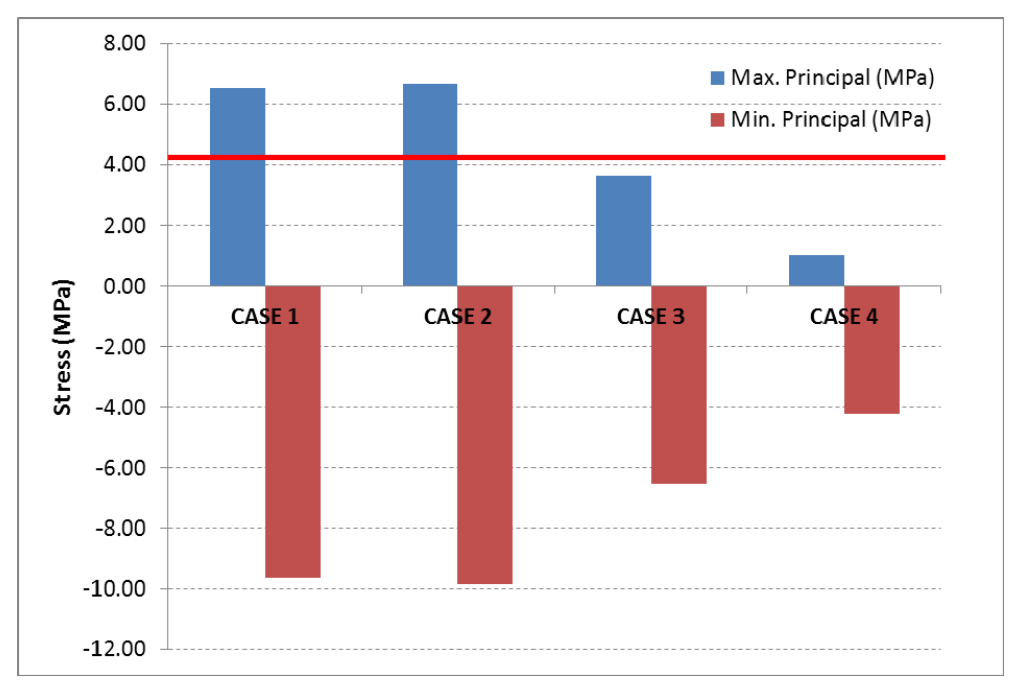

Figure 17. Max. and Min. Principal Stress in four cases

Table 3. Relative horizontal and vertical deformations

\begin{tabular}{ccc}
\hline Case No. & Relative Horizontal Deformation $(\mathrm{m})$ & Relative Vertical Deformation $(\mathrm{m})$ \\
\hline Case 1 & 0.00139 & 0.00173 \\
Case 2 & 0.00140 & 0.00175 \\
Case 3 & 0.00117 & 0.00146 \\
Case 4 & 0.00077 & 0.00100 \\
\hline
\end{tabular}

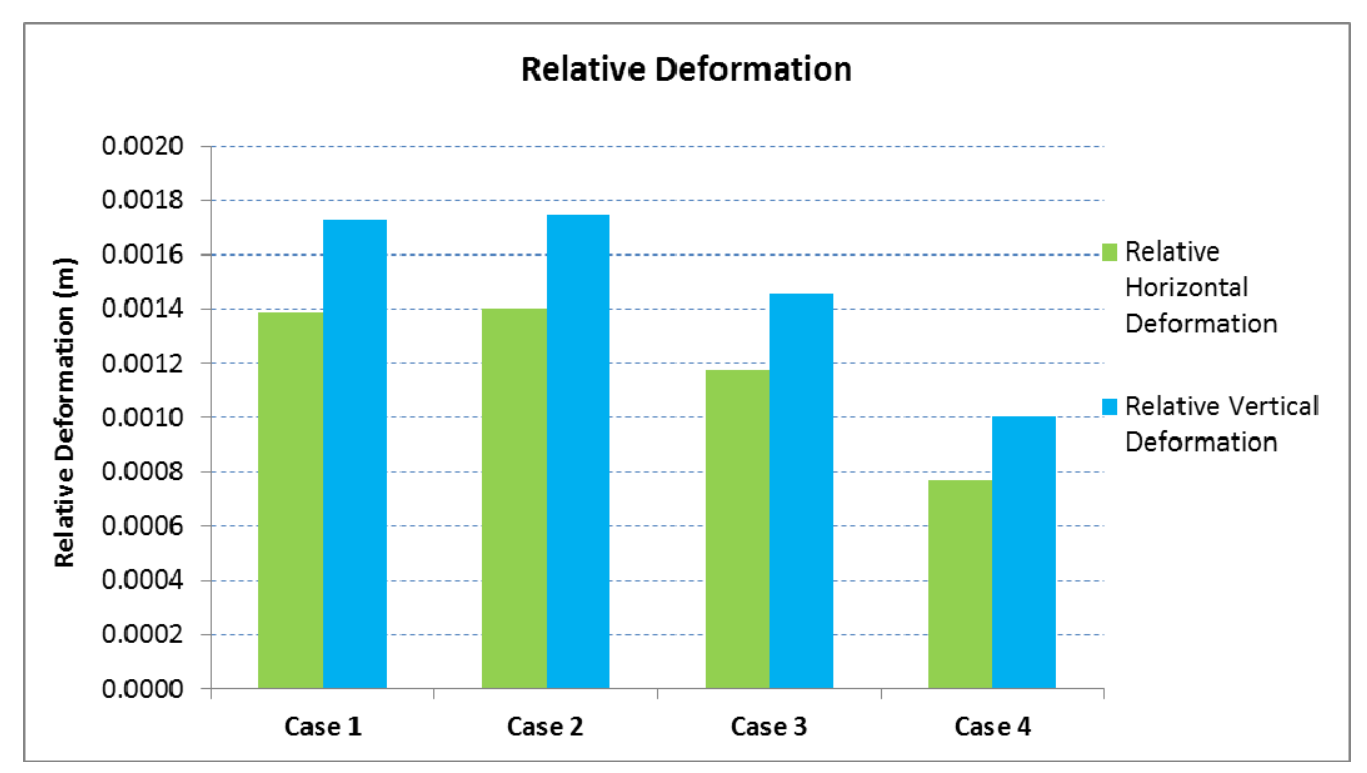

Figure 18. Relative horizontal and vertical deformations 


\section{Conclusions}

This paper presents a numerical model to analyze the effect of different bedding conditions on structural integrity of PCCP. Four cases with different bedding materials are analyzed and the results are compared. These four different bedding conditions represent typical beddings that have been found in practice. In the first two cases, the pipe is either directly placed on rock or partially placed on rock, causing high tensile stress in excess of tensile strength of concrete, thus cracks could occur at inner inverts of the pipe. According to the results, PCCP placed partially on rock has the worst tensile stress in the pipe due to high stress concentration. In the third case, the pipe is placed on a layer of sand on top of the rock, which greatly reduces the tensile stress in the pipe to the level below tensile strength of concrete and keeps the pipe safe. In the fourth case, the pipe is surrounded with soil and it has least tensile stress. The relative horizontal and vertical deformation of PCCP in four different cases is consistent with the stress level changes in four cases, namely, largest deformation in cases with rock bedding, and smaller deformation in cases with sand bedding or all soil bedding.

In sum, PCCPs should be placed on good bedding, especially in mountain areas where rock is unavoidable. Bedding treatment can be conducted by adding layers of soft material, such as Case 3 in which a layer of sand could greatly improve the stress condition in the pipe. This also indicates that pipes placed directly on rock could already have cracks due to the high tensile stress.

The findings of this research indicate the importance of good bedding for PCCP, even though this type of pipe is assumed to be "rigid". Utilities owing PCCP pipelines can use these findings to prioritize pipes in areas with poor bedding as the first layer of screening for condition assessment. Then further inspection using other advanced condition assessment technologies can be used to find defects such as cracks of the pipe before they evolve into pipe failures. The research presented in this paper could provide guidance in future model development of PCCP for condition evaluation as well.

\section{Acknowledgement}

The development of WATERiD (WATER Infrastructure Database) is funded by the Water Environment Research Foundation (WERF) under the contract INFR9SG09 and INFR10SG09 through the U.S. Environmental Protection Agency's Aging Water Infrastructure Research Program, and stems from EPA's Sustainable Water Infrastructure Initiative. The authors would like to thank the National Science Foundation (NSF) for the partial funding under the grant NSF-CMMI-0801018. We would also like to thank the support of the Sustainable Water Infrastructure Management (SWIM) Center of Excellence in the Institute of Critical Technology and Applied Science (ICTAS) at Virginia Tech. Our special thanks to the representatives of various Drinking Water and Wastewater Utilities, WATERiD Database User Group (DUG), US EPA Innovative Infrastructure Review Committee (IIRC), and WERF Project Sub-Committee (PSC) for a very thorough review that provided valuable feedback and comments related to WATER $i$ D project. The authors quite appreciate the constructive discussions with Mr. Mike Woodcock from Washington Suburban Sanitary Commission,Mr. John Marshall from J. W. Marshall and Associates, and Mr. Richard Lewis from Lewis Engineering and Consulting, Inc..

\section{References}

Alavinasab, A., Padewski III, E., Holley, M., \& Jha, R. (2010). Damage identification based on vibration response of prestressed concrete cylinder pipes. Pipelines, 2010, 909-919.

Amaitik, N. M., \& Amaitik, S. M. (2008). Development of PCCP wire breaks prediction model using artificial neural networks. Pipelines, 2008, 1-11.

AwwaRF. (2008). Failure of Prestressed Concrete Cylinder Pipe, C301-07. AWWA Research Foundation, Denver, CO.

AWWA C301-07. (2007). AWWA Standard for Prestressed Concrete Cylinder Pipe, Steel-Cylinder Type. American Water Works Association, Denver, CO.

ANSI/AWWA C304-07. (2007). Design of Prestressed Concrete Cylinder Pipe, American Water Works Association, Denver, CO.

Bell, G. E. C., Kendall, D. R., \& Mulligan, S. B. (2001). An assessment and reliability program for PCCP. Pipelines, 2001, 1-10.

Bradish, B. M., Cronin, R. J., \& Lewis, R. O. (1995). When should PCCP with Interpace Class IV wire be replaced? In J. Jeypalan (Ed.), Advances in Underground Pipeline Engineering (pp. 156-167). NY: ASCE.

Diab, Y. G., \& Bonierbale, T. (2001). A numerical modeling and a proposal for rehabilitation of PCCP's. Pipelines, $2001,1-8$. 
Erbay, O. O., Zarghamee, M. S., \& Ojdrovic, R. P. (2007). Failure risk analysis of line cylinder pipes with broken wires and corroded cylinder. Pipelines, 2007, 1-10.

Essamin, O., El-Sahli, K., Hovanessian, G., \& LeDiouron, T. (2005). Risk Management System for Prestressed Concrete Cylinder Pipeline: Practical Results and Experience on the Great Man Made River. Pipelines, 2005, 241-251.

FoxNews. (2008). Water Main Break Traps Commuters. Retrieved May 9th, 2014 from http://www.foxnews.com/photoessay/0,4644,6071,00.html/\#/photoessay/image/1223080912_M_122308_W atermain 07 -jpg

Galleher, J. J., \& Stift, M. T. (1998). Internal Inspection and Database Development of PCCP. Pipelines in the Constructed Environment, 721-730. ASCE, Reston, VA.

Ge, S., \& Sinha, S. (2014). Failure Analysis, Condition Assessment Technologies, and Performance Prediction of Prestressed Concrete Cylinder Pipe (PCCP): A State-of-the-Art Literature Review. J. Perform. Constr. Facil., 28(3), 618-628. http://dx.doi.org/10.1061/(ASCE)CF.1943-5509.0000424

Gomez, R., Munoz, D., Vera, R., \& Escobar, J. A. (2004). Structural model for stress evaluation of prestressed concrete pipe of the Cutzamala system. Pipelines, 2004, 1-9.

Kleiner, Y., Sadiq, R., \& Rajani, B. (2004). Modeling failure risk in buried pipes using fuzzy Markov deterioration process. ASCE International Conference on Pipeline Engineering and Construction, San Diego, CA., 1-12. http://dx.doi.org/10.1061/40745(146)7

Kola, R. (2010). Development of predictability and condition assessability indices for PCCP water mains, Master Thesis, Virginia Polytechnic Institute and State University, Blacksburg, VA.

Lee, Y. (2011). Analysis of prestressed concrete cylinder pipe for rehabilitation. Ph.D. Dissertation, University of California, Irvine, California, USA.

Lewis, R. A. (2002). "Improving prestressing wire reliability in prestressed concrete cylinder pipe." Materials Performance, 41(7), 48-54.

Marshall, D. H., Zarghamee, M., Mergalas, B., \& Kleiner, Y. (2005). Tarrant regional water district's risk management plan for Prestressed Concrete Cylinder Pipe. Pipelines 2005, 853-861. ASCE, Reston, VA.

Nelson, R. E. (2005). Utilizing Condition Assessment Data in Pipeline Replacement and Investment Planning. Pipelines, 2005, 130-136.

Price, R. E., Lewis, R. A., \& Erlin, B. (1998). Effects of environment on the durability of prestressed concrete cylinder pipe. Pipelines in the constructed environment, Proceedings of the 1998 Pipeline Division Conference, 584-593.

Rajani, B., Kleiner, Y., \& Sadiq R. (2006). Translation of pipe inspection results into condition ratings using the fuzzy synthetic evaluation technique. Journal of Water Supply: Research and Technology - AQUA, 55(1), $11-24$.

Rauniyar, S. (2013). Development of finite element model for analysis of prestressed concrete cylinder pipe embedded cylinder pipe. M.S. Thesis, University of Texas at Arlington, Texas, USA.

UIM. (2011). Prestressed Pipe Deterioration Prompts Large Utility to Seek Effective, Cost-efficient Approach. Retrieved Dec. 29th, 2013, from http://uimonline.com/index/webapp-stories-action/id.563/archive.yes/Issue. 2011-10-01/title.prestressed-pipe-deterioration-prompts-large-utility-to-seek-effective,-cost-efficient-approa ch

USEPA. (2013). Miami-Dade County Clean Water Act Settlement. Retrieved May 9th, 2014 from http://www2.epa.gov/enforcement/miami-dade-county-clean-water-act-settlement

Wardany, R. A. (2008). Condition assessment of prestressed concrete cylinder water pipes. Proceedings of 60th Annual WCWWA Conference and Trade Show, 1-9.

Weare, R. E. (2007). PCCP sewerage force main structural condition assessment and asset management approach. Pipelines 2007: Advances and Experiences with Trenchless Pipeline Projects, 1-11.

Woodcock, M. (2008a). 48-inch PCCP Pipeline Break, Technical report, Washington Suburban Sanitary Commission, Laurel, Maryland.

Woodcock, M. (2008b). 66-inch Water Main Break, Technical report, Washington Suburban Sanitary Commission, Laurel, Maryland. 
WSSC (2012). 80 foot setback, Washington Suburban Sanitary Commission, Laurel, Maryland. Retrieved Sept., 18, 2014 from http://www.wsscwater.com/file/EngAndConst/80footsetbackparts/part2.pdf

Xiong, H., Li, P. H., \& Li, Q. B. (2010). FE model for simulating wire-wrapping during prestressing of an embedded prestressed concrete cylinder pipe. Simulation modeling practice and theory, 18(5), $624-636$. http://dx.doi.org/10.1016/j.simpat.2010.01.007

Zarghamee, M. S., Rasko, P., Ojdrovic, R. P., \& William, D. (1993). Preventing coating delamination in prestressed concrete pipe. Proceedings of the ASCE pipeline division conference : Pipeline infrastructure II, San Antonio, TX, 574-594.

Zarghamee, M. S., \& Ojdrovic, R. P. (2001). Risk assessment and repair priority of PCCP with broken wires. Pipelines, 2001, 1-8.

Zarghamee, M. S., Eggers, D. W., \& Ojdrovic, R. P. (2002). Finite element modeling of failure of PCCP with broken wires subjected to combined loads. Pipelines, 2002, 1-17.

Zarghamee, M. S., Eggers, D. W., Ojdrovic, R. P., \& Rose, B. (2003). Risk analysis of prestressed concrete cylinder pipe with broken wires. Pipelines, 2003, 599-609.

Zarghamee, M. S., Erbay, O. O., Eggers, D. W., \& Kendall, D. R. (2006). Ultimate strength prediction of steel liners using nonlinear finite element analysis. Pipelines, 2006, 1-9.

\section{Copyrights}

Copyright for this article is retained by the author(s), with first publication rights granted to the journal.

This is an open-access article distributed under the terms and conditions of the Creative Commons Attribution license (http://creativecommons.org/licenses/by/3.0/). 